\title{
Senescence as a Target for Cancer Therapy
}

\author{
Hiroshi Kondoh ${ }^{*}, 1$ Takeshi Maruyama ${ }^{1}$ and Matilde E. Lleonart ${ }^{*}, 2$
}

\author{
${ }^{I}$ Department of Geriatric Medicine Graduate School of Medicine, Kyoto University, 54 Kawahara-cho, Shogoin, \\ Sakyo-ku, Kyoto, 606-8507, Japan \\ ${ }^{2}$ Pathology Department, Fundació Institut de Recerca Hospital Vall d'Hebron, Passeig Vall d'Hebron 119-129, 08035 \\ Barcelona, Spain
}

\begin{abstract}
Primary mammalian cells reach replicative exhaustion after several passages in vitro, a process called replicative senescence. During such a state of permanent growth arrest, senescent cells are refractory to physiological proliferation stimuli with altered cell morphology and gene expression patterns, although they remain viable with preserved metabolic activity. Interestingly, senescent cells have also been detected in vivo in human tumors, particularly in benign lesions. Tumor suppressor genes are closely involved in senescence, as their knockdown and ectopic expression confer immortality and senescence induction, respectively. By using high throughput genetic screenings to search for genes involved in senescence, several candidate oncogenes and putative tumour suppressor genes have been isolated recently, including subtypes of miRNAs. Senescence is thus an anti-tumorigenic mechanism for avoidance of indefinite cell proliferation when an oncogenic alteration has occurred. In this review, we remark how these findings offer new perspectives in the modulation of senescence and open new approaches for cancer therapy.
\end{abstract}

\section{INTRODUCTION}

Approximately one in four people in the developed world experience cancer during their life time. From the pathological and clinical view point, the process of tumorgenesis in vivo consists of three or more stages; immortalization, transformation, invasion, and metastasis. During immortalization, several biological events are supposed to be required; bypassing senescence, evasion of apoptosis and anti-growth signals, growth factor independence and so on. Following immortalization, to grow more aggresively and three dimentionally in vivo, these immortalized cells should be transformed to be anchorage-independent, resistant to contact inhibition and angiogenesis. In the final stages, the transformed cells detach from one another and subsequently degrade matrix components and then invade other tissues (metastasis). All these properties are also distinct hallmark of cancerous cells, compared with their normal counterpart.

These properties could possibly be good targets for anticancer drugs, such as DNA damaging, anti-angiogenic, differentiation-inducing, or apoptosis-inducing agents. Recent progress in the biology of cellular senescence provides another clue to understanding the mechanism of cancer progression as well as to developing new anti-cancer drugs.

Primary mammalian cells reach proliferative exhaustion after serial passage in culture, resulting in a permanent and irreversible cell-cycle arrest [1]. This process, called replicative senescence, is characterized by a drastic phenotypic

*Address correspondence to these authors at the (HK) Department of Geriatric Medicine Graduate School of Medicine, Kyoto University, 54 Kawahara-cho, Shogoin, Sakyo-ku, Kyoto, 606-8507, Japan;

E-mail: hkondoh@kuhp.kyoto-u.ac.jp; and (MEL) Pathology Department, Fundació Institut de Recerca Hospital Vall d'Hebron, Passeig Vall d'Hebron 119-129, 08035 Barcelona, Spain; E-mail: melleona@ir.vhebron.net change in senescent cells, compared to their proliferating counterparts $[2,3]$. The transition to the senescent phenotype is studied in culture where the cell population can be grown and monitored. Features of senescent cells are the presence of $\beta$-galactosidase positive cells, PAI- 1 overexpression (plasminogen activator protein 1) and altered cell morphology of giant cells with a single large nucleus (Fig. 1). Cells experiencing senescence in any case cannot be stimulated to re-enter the cell cycle by physiological mitogens, although they are viable.

During several decades, it was thought that senescence occurred as a consequence of culture shock of primary cells from in vivo to in vitro transition. However, interestingly, senescent cells have recently been detected in tumorigenesis in mouse models and in human tumors, particularly in benign lesions $[4,5]$, and their appearance is possibly relevant to tumor progression. There are examples of in vivo senescent cells that may reside for years in tissue, such as the senescent melanocytes of moles of nervi. In contrast, other senescent cells can be rapidly removed as tumors progress, for example in the case of liver carcinomas $[6,7]$.

As senescence is a biological process that occurs in life organisms, the cellular senescence observed in tissue culture might constitute a good model for understanding the significance of senescence in vivo. Recent attempts at senescence bypass screenings have identified several putative novel oncogenes and tumor suppressor genes (Fig. 1). Genes whose ectopic expression bypasses replicative senescence are considered potential oncogenes [8] as the proteins encoded by such genes are detected in highly immortalized cells and overexpressed in some types of cancer $[9,10]$. On the other hand, genes whose inactivation immortalizes cells are potential tumor suppressor genes [11] and are found to be downregulated in tumor-resident tissues [12]. Therefore, senescence is considered as an anti-tumorigenic mechanism for 


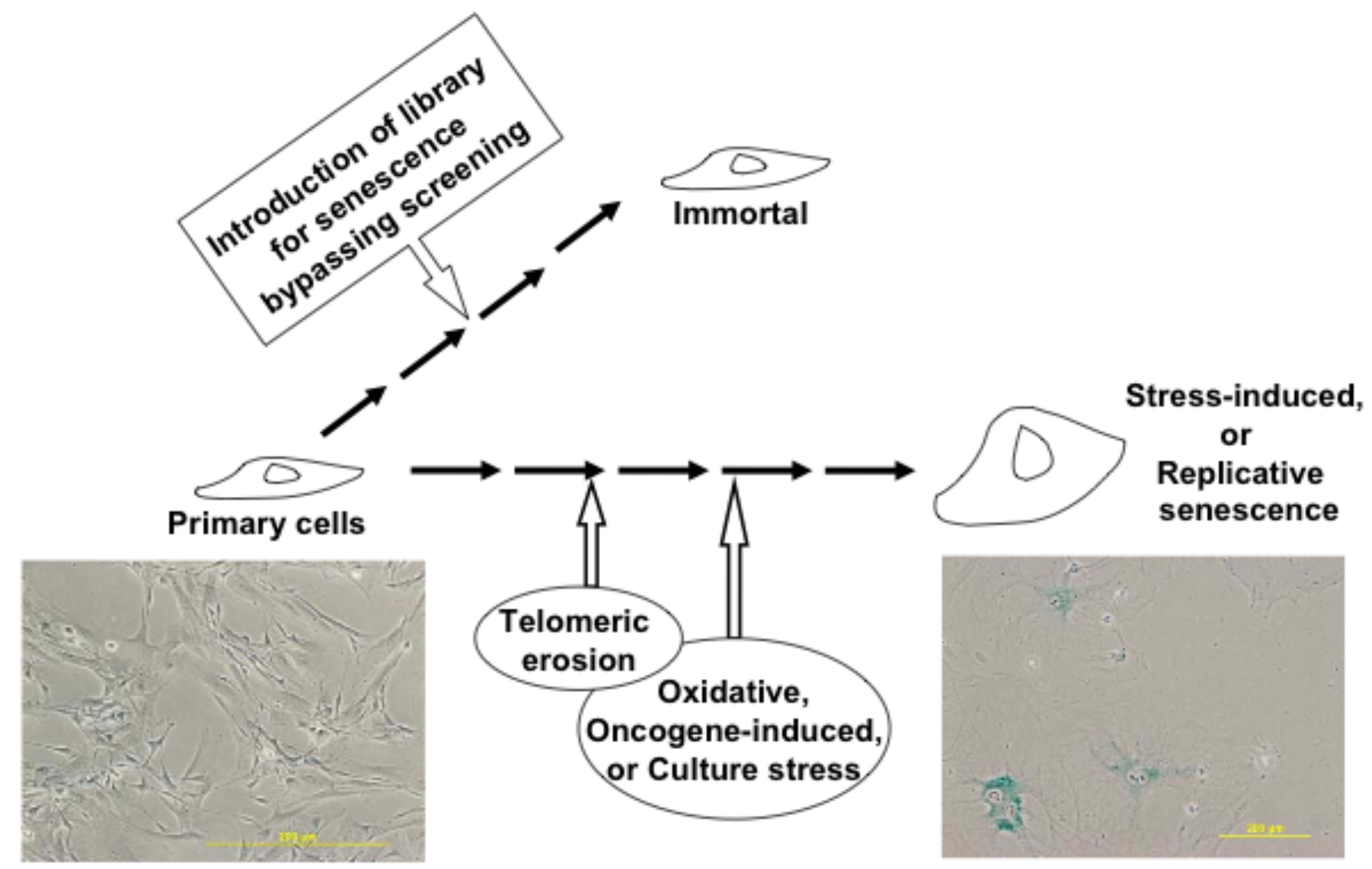

Fig. (1). Senescence bypass screening. Phenotypic characteristics of primary (left bottom) versus senescent (right bottom) MEF cells are shown upon fixation and staining with $\beta$-galactosidase.

avoiding indefinite cell proliferation when a genetic alteration has occurred. This fact suggests that senescenceinducing mechanisms can be applicable as cancer therapies in the future by arresting proliferation of tumorigenic cells by senescence induction. Here, we will review recent advances in senescence biology, which may contribute to the development of new cancer drugs.

\section{TELOMERE-DEPENDENT SENESCENCE}

Human telomeres consist of tandem repetitive arrays of the hexameric sequence TTAGGG, with overall telomere sizes ranging from $15 \mathrm{~kb}$ at birth to $<5 \mathrm{~kb}$ as telomeres become progressively shorter with every round of cell division in normal cells [13]. The ends of telomeres are protected and regulated by telomere-binding proteins and form a special lariat-like structure called the T-loop. Telomerase is a cellular ribonucleoprotein enzyme responsible for adding telomeric repeats onto the 3 'ends of chromosomes. It has two major components, an enzymatic human telomerase transcriptase catalytic subunit hTERT, and a RNA component hTERC. Telomerase uses its integral RNA component as a template in order to synthesize telomeric DNA directly onto the ends of chromosomes. The enzyme is normally expressed in very few primary cells such as embryonic stem cells, while the hTERT gene undergoes silencing and enzymatic activity is repressed during differentiation of these cells [14]. Telomerase is also present in adult male germline cells, but is undetectable in most normal somatic cells except for proliferative cells of renewal tissues.
Primary normal human cells stably expressing transfected telomerase can divide indefinitely, providing direct evidence that telomere shortening has a causal effect on replicative senescence [15]. As such, replicative senescence is a consequence of telomere shortening and dysfunction due to the inability of human cells to replicate the chromosomal ends (Greider and Blackburn 1996; Serrano and Blasco, 2001).

Telomerase is also involved in several human diseases, such as dyskeratosis congenital or aplastic anemia, which are caused by the mutations in genes encoding components of telomerase or telomere-binding proteins. These mutations cause low telomerase activity, accelerated telomere shortening, and diminished proliferative capacity of hematopoietic progenitors.

Interestingly, telomerase is detected in approximately $90 \%$ of all malignant tumors, suggesting that telomerase can be a suitable target for anti-cancer drugs. Several clinical trials targeting telomerase are ongoing for advanced cancer patients. These include immunotherapy (a vaccine against telomerase), inhibitory compounds against telomerase activity (a telomerase template antagonist), and the modulation of telomeric structure (telomestatin) [16, 17]. The expected outcome of telomerase inhibition should not only be slower tumor growth, but also the possibility of induced apoptosis, for the following reasons: Tumor suppressor p53 is presumed to sense dysfunctional telomeres as damaged DNA, whereupon it elicits the senescence response at least in part 
by increasing expression of the $\mathrm{p} 21^{\mathrm{Cip} 1}$ protein, that in turn prevents the inactivation of p53 $[18,19]$. Thus, it would be expected that in p53-intact cells, accelerated telomeric shortening by telomerase inhibitors could be sensed by the p53 pathway and would be followed by massive apoptotic death. Moreover the possibility that telomerase inhibitors could be combined with other chemotherapeutical drugs to increase anti-cancer therapy is a challenge proposal that deserves to be fully explored in clinical trials.

\section{TELOMERE-INDEPENDENT SENESCENCE}

Cellular senescence is a process that is triggered not only by telomeric erosion, but also by other causes. Several factors provoke senescence in a telomere-independent manner: stress-induced senescence (SIS), including DNA damage and oxidative stress, or oncogene-induced senescence (OIS) induced by oncogenic activation.

In contrast to telomere-dependent senescence, when senescence is induced by a stimulus such as oncogenic Ras, Raf, epigenetic changes or oxidative damage, the ectopic expression of hTERT cannot confer the senescencebypassing effect [20]. However, in several cases of telomereindependent senescence, the initiating event can be triggered by a common mechanism. For example, cellular damage caused by these stresses would be recognized by cellular sensors of the DNA damage checkpoint apparatus, leading to the activation of cell cycle checkpoint responses, the ataxia telangiectasia mutated ATM-Chk2 kinase and ATR/Chk1 signaling, and recruitment of DNA repair foci. Tumor cells in clinical specimens from various tissues, for example in breast and lung carcinomas, often show constitutive activation of DNA damage signaling, such as activated forms of checkpoint kinases ATM and Chk2, phosphorylated histone $\mathrm{H} 2 \mathrm{AX}$ and $\mathrm{p} 53$, and foci formation by proteins as 53BP1 $[21,22]$. Activation of DNA damage signaling may be followed by the formation of senescence-associatedheterochromatin foci (SAHFs). SAHFs accumulate during oncogene-induced senescence and are thought to stably suppress the expression of E2F target genes by recruiting $\mathrm{Rb}$ and heterochromatin proteins [23].

Of note is that SIS and OIS can be bypassed partially by inactivation of tumor suppressors, including the p53 or $\mathrm{Rb}$ axis, implicating the involvement of tumor suppressor genes in these stress-induced senescence processes (Fig. 2). Thereby, tumor suppressor activation can be another target of cancer therapy in vivo $[2,4,24]$. Promising results have been recently reported in a murine model where complete tumor regression could be provoked by p53 activation [7, 25, 26]. In vitro restoration of $\mathrm{p} 53$ function triggers dramatic and rapid induction of p53 target genes, as well as apoptosis. While several groups have reported similar effects, it is not just p53 status itself that determines therapeutic efficacy of p53 restoration, but also the status of p53-activating signals that pre-exist, or can be induced, in tumor cells. Although this situation would not be exactly the same as that which occurs in human cancer (where p53 is affected or the p53 pathway is corrupted), regression of these tumours was closely correlated with the presence of senescent cells. These studies provide the first evidence that senescence induction in vivo can be a crucial mechanism of tumor clearance. Thus it would be worthwhile to further investigate whether p53 activating chemicals, such as quinacrine, can be beneficial for cancer patients.

\section{ONCOGENE-INDUCED SENESCENCE (OIS)}

One of the tumorigenesis barriers that slow or inhibit the progression of preneoplasic lesions involves DNA replication stress and a second barrier is mediated by OIS. Although the relationship between these two barriers has not been elucidated, OIS has been reported to be associated to signs of DNA replication stress including DNA doublestrand breaks [27]. Several oncogenes are known to induce a senescence response upon overexpression: Ras, Raf, MEK, Atk, E2F1/3, mos, PTEN, NF1, Stat5, KLF-4, and Runx. Ectopic expression of these genes triggers senescence while its inhibition in most cases correlates with senescence bypass.

The most well-defined model of oncogene inducedsenescence is shown by an activated allele of the ras gene $\left(\operatorname{Ras}^{\mathrm{V} 12}\right.$ ) whose overexpression is accompanied by a concomitant accumulation of $\mathrm{p} 53$ and $\mathrm{p} 16^{\mathrm{INK} 4 \mathrm{~A}}$ proteins [3]. In animal models it has been shown that adenomas from mice expressing a single activated K-Ras allele undergo senescence in vivo [4]. Sarkisian et al. [28] have show the importance of the intensity of the ras pathway by demonstrating that only high levels of activated H-Ras trigger senescence in human mammary epithelial cells in vivo.

Recent findings suggest that these OIS can be provoked in a cellular context-dependent manner and also the response may differ depending on murine or human cells. For example, inactivation of NF1, a gene responsible for familial cancer syndrome neurofibromatosis type I, results in immortalization of MEFs cells. In contrast, NF1 inactivation in human diploid fibroblasts induces senescence as a result of negative feedback regulation. Importantly, NF1 deficiency also induces senescence in vivo, in cells within benign human tumors from patients with NF1 [29]. Other representative study from Sansom et al. [30] have shown that the expression of a single, activated K-ras allele in mice was insufficient to trigger Akt or ERK activation in the intestine, but enough to induce potent Akt and ERK activation in the kidney and to drive renal cell carcinoma in cooperation with APC mutations [31].

As most of the studies of senescence induced by oncogenes have been performed in primary cells in culture, thereby in a wild-type background, the above mentioned lines of evidence suggest that the stimuli for oncogeneinduced senescence can accelerate tumor progression in some contexts. Thus, we hypothesize that the modulation of these targets is supposed to be rather risky or less effective for cancer therapy.

\section{SENESCENCE INDUCTION BY TUMOR SUPPRES- SOR GENES}

In cancerous cells or tissues, tumor suppressor genes may be inactivated by either deletion of one or both alleles, promoter methylation, splice-site mutations or nonsense mutations and the like (or a combination of these). Alternatively, mutations in tumor suppressor genes can provide a dominant negative protein interfering the wild-type protein produced by the other allele as is the case of several p53 mutants. Such genetic alterations result in a complete absence or partial 


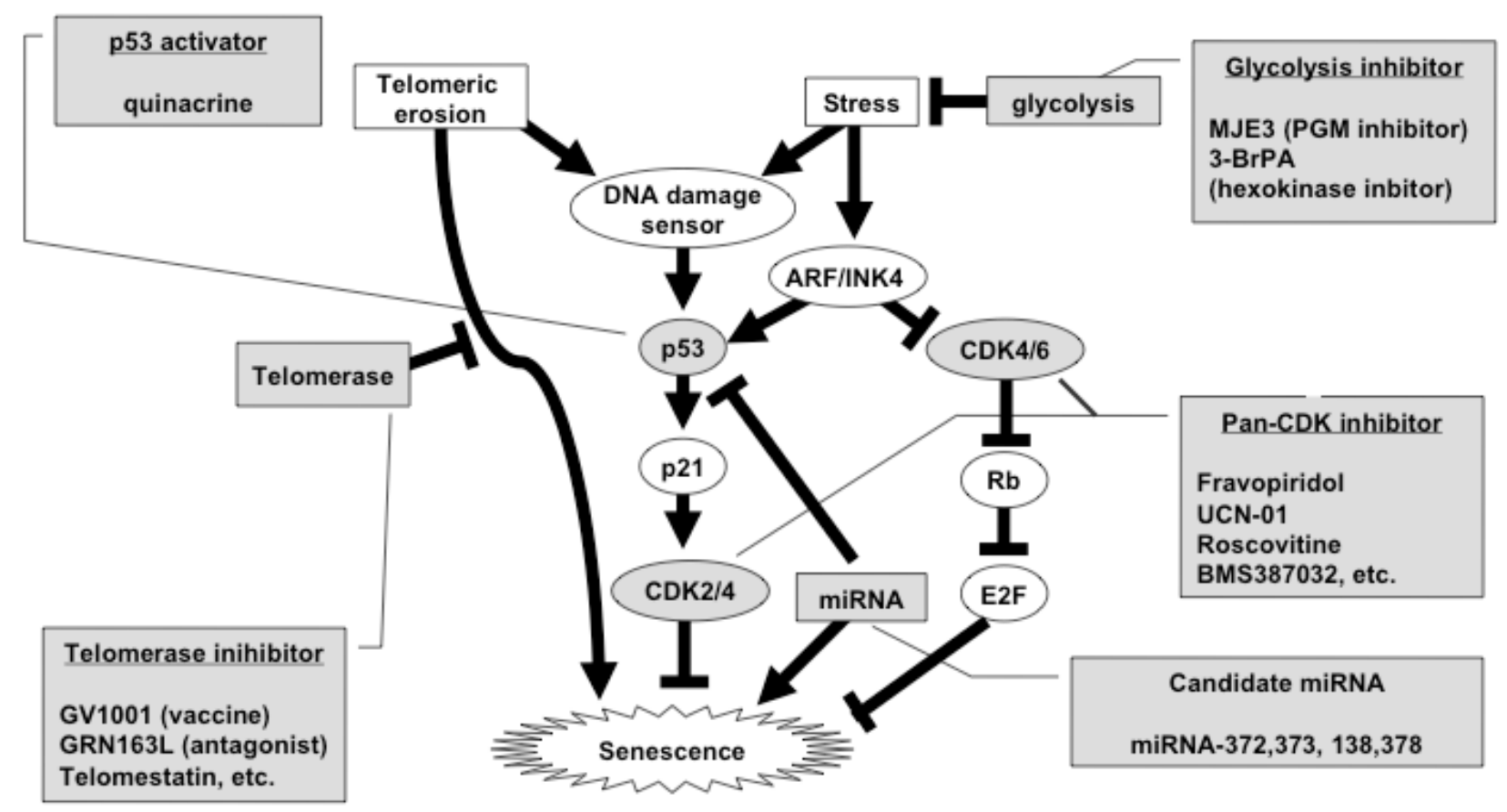

Fig. (2). Senescence inducing factors as targets of cancer therapy. Details are described in the text.

reduction of the tumor suppressor protein, conferring selective advantage in clonal selection for tumor progression. Given the fact that p53 is one of the most mutated or deleted genes in human tumors, we hypothesize that it would be rather difficult to target p53 itself as an anti-cancer therapy in human cancers. Alternatively, proteins upstream or downstream of p53 pathway are also targets for this purpose.

The most representative tumor suppressor locus upstream p53 is the ARF/INK4a (Alternative Reading Frame) that encodes two distinct tumor suppressors ARF (p14 ${ }^{\mathrm{ARF}}$ in humans and $\mathrm{p} 19^{\mathrm{ARF}}$ in mice) and $\mathrm{p} 16^{\mathrm{INK} 4 \mathrm{~A}}$. Inherited predisposition to melanoma gave the first clue that the chromosomal region of 9p21 contained putative suppressor genes identified at ARF/INK4a locus [32]. Interestingly, p16 ${ }^{\mathrm{INK} 4 \mathrm{~A}}$ and $\mathrm{p} 19^{\mathrm{ARF}}$ respectively regulate the $\mathrm{pRB}$ and $\mathrm{p} 53$ pathways of senescence and tumor suppression. The tumor suppressor activity of p $16^{\text {INK4A }}$ is based on its ability to bind and inhibit cyclin-Ddependent kinases CDK4 and CDK6. Such kinases have oncogenic potential and phosphorylate the retinoblastoma family of tumor suppressors Rb, p107 and p130, which are negative regulators of the cell cycle (Fig. 2) [33]. On the other hand, $\mathrm{p} 19^{\mathrm{ARF}}$ regulates $\mathrm{p} 53$ stability through the inactivation of the p53-degrading ubiquitin ligase $\mathrm{mdm} 2$. This process is inhibited by $\mathrm{p} 19^{\mathrm{ARF}}$ through translocation of $\mathrm{mdm} 2$, provoking $\mathrm{p} 53$ stabilization.

During replicative senescence in vitro, the accumulation of these tumor suppressors $\left(\mathrm{p} 53, \mathrm{p} 19^{\mathrm{ARF}}, \mathrm{p} 16^{\mathrm{INK} 4 \mathrm{~A}}\right)$ or their downstream targets $\left(\mathrm{p} 21^{\mathrm{Cip} 1}\right)$ is observed and reach their maximal levels concomitantly to the presence of $\beta$ galactosidase positive cells. In agreement with that observation, it is noteworthy that the ectopic expression of these tumor suppressors ( $\mathrm{p} 19^{\mathrm{ARF}}, \mathrm{p} 16^{\mathrm{INK} 4 \mathrm{~A}}, \mathrm{p} 21^{\mathrm{Cip} 1}$ ) can provoke a senescence-like phenotype in primary or immortalized cells.

Collectively, these senescence-inducing tumor suppressor genes can also be targets of anti-cancer drugs. Several
ARF/INK4A locus transcriptional repressors have been identified in a senescence bypass screen as TBX2 [34] and Zbtb7 or pokemon for $\mathrm{p} 19^{\mathrm{ARF}}$ and $\mathrm{CBX} 7$ for $\mathrm{p} 16^{\mathrm{INK} 4 \mathrm{~A}}$ [35]. Thereby inhibition of the latter could be used for senescence induction by allowing $\mathrm{p} 19^{\mathrm{ARF}}$ and $\mathrm{p} 16^{\mathrm{INK} 4 \mathrm{a}}$ upregulation respectively. However, as is often the case in p53, the inactivation of the ARF/INK4a locus by complete deletion or by aberrant promoter methylation is very common, about $30 \%$ in essentially all known types of malignancies. Presumably, in cancer cells harboring genetic inactivation of this locus, the modulation of ARF/INK4A function would be less effective or impossible, although it would be interesting to target this unifying tumor suppressor locus so as to affect both the $\mathrm{p} 53$ and $\mathrm{Rb}$ axis.

Alternatively, a CDK inhibitor can be a good tool, as both the ARF/p53 and INK4A/Rb axis exert their tumor suppressing function partially via inactivation of CDK4. Currently several small chemical modulators for CDK kinases are under investigation in clinical trials. So far, all of these are not CDK4-specific inhibitors, but rather pan-CDK inhibitors, such as Fravopiridol, UCN-01, Roscovitine, and BMS387032 [36, 37]. Their anti-cancer effects mainly result in induction of apoptosis rather than provocation of senescence possibly because CDKs play additional and essential roles other than cell cycle control, including transcription, DNA repair, migration, and secretion. As gene therapy by the use of virus has been discarded as an effective tool for cancer therapy (due to the possibility that viruses can induce additional genetic modifications), we speculate that the use of siRNA (small interference RNAs) of negative regulators of $\mathrm{p} 19^{\mathrm{ARF}}$ or $\mathrm{p} 16^{\mathrm{INK} 4 \mathrm{~A}}$ could be effective to induce senescence in vivo.

\section{SENESCENCE AND miRNAs}

Micro-RNAs (miRNA) are short, 22-nucleotide, noncoding RNAs that are thought to regulate gene expression by sequence-specific base pairing in the 3 '-untranslated regions 
(UTR) of a target mRNA, including direct mRNA degradation or translational inhibition [38]. miRNA expression patterns are developmentally regulated, tissue specific, or steadily expressed in the whole organism and are considered to play important roles in cell proliferation, apoptosis and differentiation. Bioinformatics approaches have identified 300 human miRNA genes, but more recent work has predicted the number to be closer to 1,000 [39] and one-third of all human mRNAs appear to be miRNA targets.

Several studies implicating miRNAs directly in cancer are emerging, which is assumed given the fact that cancers ultimately arise because of disrupted gene expression [40-42]. Recent studies have shown that miRNA expression profiles are different between normal and tumoral tissues and between different tumor types. Interestingly, downregulation of subsets of miRNAs is a common finding in some tumors. The discovery that miRNA silencing could revert the tumorigenic phenotype of the colon cancer cell line HCT116 unveils a novel regulatory mechanism in cancer proliferation [42]. The presence of methylated versus unmethylated miRNAs in normal versus tumoral tissue mimics similar silencing strategies for other tumour suppressor genes such as $\mathrm{p} 16^{\mathrm{INK} 4 \mathrm{~A}}$. The miRNA34 family is involved in the p53 tumor suppressor network [43], thereby it would not be surprising that senescence could be also modulated by miRNAs. In agreement with such assumption, a genetic screen designed to identify miRNAs characterized by their ability to bypass senescence induced by oncogenic Ras (OIS), miR-372 and miR-373 have been identified [44]. Interestingly, such microRNAs are overexpressed in testicular germ cell tumors in humans which harbour an embryonic stem cell signature. These miRNAs are putative novel oncogenes participating in the development of human tumors by numbing the p53 pathway and promoting tumorigenic growth in the presence of wild-type p53. Moreover the function of micro-RNAs miR-373 and miR-520e promoting tumor invasion and metastasis has been recently reported in breast cancer patients [45].

On the other hand, downregulation of miR-138 is associated with overexpression of telomerase and the acquisition of malignant behaviour in human anaplastic thyroid carcinoma cell lines [46]. Thereby, it is expected that targeting miR-138 would be useful as a diagnostic tool or might contribute to the development of new strategic treatments for specific kinds of carcinomas as already suggested for miR-378 [47].

\section{GLYCOLYSIS AND SENESCENCE}

Based on the phenotypic characteristics of senescent cells, large-scale genetic screenings can be performed in vitro in order to identify novel oncogenes and tumor suppressor genes involved in cell proliferation (Fig. 1). By using such a genetic approach, several proliferative-promoting genes have been discovered that are also involved in human cancer [8, 12, 48]. We have demonstrated that a protein designated phosphoglycerate mutase (PGM) is able to bypass senescence and immortalize primary MEFs by increasing glycolysis and protecting them from oxidative damage. Moreover the tumor suppressor p53 post-transcriptionally controls the level of the glycolytic enzyme PGM $[8,48]$, suggesting that PGM can be a key enzyme in a cellular context-dependent manner.

Since enhanced glycolysis is a well known property of most cancerous cells and tissues, commonly referred to as the
Warburg effect, such property is well utilized in clinical practice for the detection of metastatic tumor mass through positron-emission scanning of 2-[ $\left.{ }^{18} \mathrm{~F}\right]$ fluoro-2-deoxy-D-glucose [49]. Therefore, glycolytic inhibitors are candidate strong tools for anti-cancer therapy. Indeed, the PGM inhibitor MJE3 has been identified as the most potent anti-proliferative reagent via chemical screening in breast cancer cells [50]. One large problem with such reagents is that glycolytic inhibition can damage certain organs, especially the brain, as glycolysis is an important energy source for cells. Tissue specific delivery of these reagents should be considered, for example, through their injection via specific feeding arteries for tumors.

In conclusion, these recent findings on senescent biology have disclosed new avenues for cancer research and senescence-related genes can be good targets for cancer therapy. The future challenge will be to design a specific cancer treatment for each patient depending on their genetic background. A personalized genetic test of the status of several tumor suppressors, including $\mathrm{p} 53, \mathrm{ARF} / \mathrm{INK} 4 \mathrm{~A}$ locus and $\mathrm{p} 21^{\mathrm{Cip} 1}$ should be carefully examined in order to consider whether a specific or a more generalized therapy should be applied. Once the status of these senescence-associated genes is known, it should be easier to predict the sensitivity or resistance of a tumor to anticancer treatment, and consequently contribute to cancer clearance.

\section{ACKNOWLEDGEMENTS}

This study was supported by a FIS project 04/0530 and Marato TV3 project 052130. M.E.LL is a FIS investigator (CP03/00101). We thank J.A. Leal for assistance with electronic submission of this manuscript.

\section{REFERENCES}

[1] Hayflick L, Moorhead PS. The serial cultivation of human diploid cell strains. Exp Cell Res 1961; 25: 585-621.

[2] Schmitt CA, Fridman JS, Yang M, et al. A senescence program controlled by $\mathrm{p} 53$ and p16INK4a contributes to the outcome of cancer therapy. Cell 2002; 109: 335-46.

[3] Serrano M, Lin AW, McCurrach ME, Beach D, Lowe SW. Oncogenic ras provokes premature cell senescence associated with accumulation of p53 and p16INK4a. Cell 1997; 88: 593-602.

[4] Collado M, Gil J, Efeyan A, et al. Tumour biology: senescence in premalignant tumours. Nature 2005; 436: 642.

[5] Hanahan D, Weinberg RA. The hallmarks of cancer. Cell 2000; 100 : 57-70.

[6] Michaloglou C, Vredeveld LC, Soengas MS, et al. BRAFE600associated senescence-like cell cycle arrest of human naevi. Nature 2005; 436: 720-4.

[7] Xue W, Zender L, Miething C, et al. Senescence and tumour clearance is triggered by $\mathrm{p} 53$ restoration in murine liver carcinomas. Nature 2007; 445: 656-60.

[8] Kondoh H, Lleonart ME, Gil J, et al. Glycolytic enzymes can modulate cellular life span. Cancer Res 2005; 65: 177-85.

[9] Lawson DA, Witte ON. Stem cells in prostate cancer initiation and progression. J Clin Invest 2007; 117: 2044-50.

[10] Pardal R, Molofsky AV, He S, Morrison SJ. Stem cell self-renewal and cancer cell proliferation are regulated by common networks that balance the activation of proto-oncogenes and tumor suppressors. Cold Spring Harb Symp Quant Biol 2005; 70: 177-85.

[11] Berns K, Hijmans EM, Mullenders J, et al. A large-scale RNAi screen in human cells identifies new components of the p53 pathway. Nature 2004; 428: 431-7.

[12] ME LL, Vidal F, Gallardo D, et al. New p53 related genes in human tumors: significant downregulation in colon and lung carcinomas. Oncol Rep 2006; 16: 603-8.

[13] Blasco MA. Telomeres and human disease: ageing, cancer and beyond. Nat Rev Genet 2005; 6: 611-22. 
[14] Wright WE, Piatyszek MA, Rainey WE, Byrd W, Shay JW. Telomerase activity in human germline and embryonic tissues and cells. Dev Genet 1996; 18: 173-9.

[15] Bodnar AG, Ouellette M, Frolkis M, et al. Extension of life-span by introduction of telomerase into normal human cells. Science 1998; 279: 349-52.

[16] Tauchi T, Shin-ya K, Sashida G, et al. Telomerase inhibition with a novel G-quadruplex-interactive agent, telomestatin: in vitro and in vivo studies in acute leukemia. Oncogene 2006; 25: 5719-25.

[17] Tauchi T, Ohyashiki JH, Ohyashiki K. Telomerase inhibition combined with other chemotherapeutic reagents to enhance anti-cancer effect. Methods Mol Biol 2008; 405: 181-9.

[18] Sherr CJ, Roberts JM. CDK inhibitors: positive and negative regulators of G1-phase progression. Genes Dev 1999; 13: 1501-12.

[19] Serrano M, Blasco MA. Putting the stress on senescence. Curr Opin Cell Biol 2001; 13: 748-53.

[20] Morales CP, Holt SE, Ouellette M, et al. Absence of cancerassociated changes in human fibroblasts immortalized with telomerase. Nat Genet 1999; 21: 115-8.

[21] Tommiska J, Bartkova J, Heinonen M, et al. The DNA damage signalling kinase ATM is aberrantly reduced or lost in BRCA1/BRCA2deficient and ER/PR/ERBB2-triple-negative breast cancer. Oncogene 2008; 27: 2501-6.

[22] Bartkova J, Horejsi Z, Sehested M, et al. DNA damage response mediators $\mathrm{MDC1}$ and 53BP1: constitutive activation and aberrant loss in breast and lung cancer, but not in testicular germ cell tumours. Oncogene 2007; 26: 7414-22.

[23] Adams PD. Remodeling of chromatin structure in senescent cells and its potential impact on tumor suppression and aging. Gene 2007; 397: 84-93.

[24] Dimri GP, Testori A, Acosta M, Campisi J. Replicative senescence, aging and growth-regulatory transcription factors. Biol Signals 1996; 5: 154-62.

[25] Ventura A, Kirsch DG, McLaughlin ME, et al. Restoration of p53 function leads to tumour regression in vivo. Nature 2007; 445: 661-5.

[26] Martins CP, Brown-Swigart L, Evan GI. Modeling the therapeutic efficacy of p53 restoration in tumors. Cell 2006; 127: 1323-34.

[27] Bartkova J, Rezaei N, Liontos M, et al. Oncogene-induced senescence is part of the tumorigenesis barrier imposed by DNA damage checkpoints. Nature 2006; 444: 633-7.

[28] Sarkisian CJ, Keister BA, Stairs DB, Boxer RB, Moody SE, Chodosh LA. Dose-dependent oncogene-induced senescence in vivo and its evasion during mammary tumorigenesis. Nat Cell Biol 2007; 9: 493505 .

[29] Courtois-Cox S, Genther Williams SM, Reczek EE, et al. A negative feedback signaling network underlies oncogene-induced senescence. Cancer Cell 2006; 10: 459-72.

[30] Sansom OJ, Meniel V, Wilkins JA, et al. Loss of Apc allows phenotypic manifestation of the transforming properties of an endogenous K-ras oncogene in vivo. Proc Natl Acad Sci U S A 2006; 103: 141227.

[31] Rowland BD, Bernards R, Peeper DS. The KLF4 tumour suppressor is a transcriptional repressor of p53 that acts as a context-dependent oncogene. Nat Cell Biol 2005; 7: 1074-82.
[32] Kamb A, Gruis NA, Weaver-Feldhaus J, et al. A cell cycle regulator potentially involved in genesis of many tumor types. Science 1994; 264: 436-40.

[33] Tashiro E, Tsuchiya A, Imoto M. Functions of cyclin D1 as an oncogene and regulation of cyclin D1 expression. Cancer Sci 2007; 98: 629-35.

[34] Jacobs JJ, Keblusek P, Robanus-Maandag E, et al. Senescence bypass screen identifies TBX2, which represses Cdkn2a (p19(ARF)) and is amplified in a subset of human breast cancers. Nat Genet 2000; 26: 291-9.

[35] Maeda T, Hobbs RM, Merghoub T, et al. Role of the proto-oncogene Pokemon in cellular transformation and ARF repression. Nature 2005; 433: 278-85.

[36] Ambrosini G, Seelman SL, Qin LX, Schwartz GK. The cyclindependent kinase inhibitor flavopiridol potentiates the effects of topoisomerase I poisons by suppressing Rad51 expression in a p53dependent manner. Cancer Res 2008; 68: 2312-20.

[37] Whittaker SR, Te Poele RH, Chan F, et al. The cyclin-dependent kinase inhibitor seliciclib (R-roscovitine; CYC202) decreases the expression of mitotic control genes and prevents entry into mitosis. Cell Cycle 2007; 6: 3114-31.

[38] He L, Hannon GJ. MicroRNAs: small RNAs with a big role in gene regulation. Nat Rev Genet 2004; 5: 522-31.

[39] Berezikov E, Guryev V, van de Belt J, Wienholds E, Plasterk RH, Cuppen E. Phylogenetic shadowing and computational identification of human microRNA genes. Cell 2005; 120: 21-4.

[40] He L, Thomson JM, Hemann MT, et al. A microRNA polycistron as a potential human oncogene. Nature 2005; 435: 828-33.

[41] Lu J, Getz G, Miska EA, et al. MicroRNA expression profiles classify human cancers. Nature 2005; 435: 834-8.

[42] Lujambio A, Ropero S, Ballestar E, et al. Genetic unmasking of an epigenetically silenced microRNA in human cancer cells. Cancer Res 2007; 67: 1424-9.

[43] He L, He X, Lim LP, et al. A microRNA component of the p53 tumour suppressor network. Nature 2007; 447: 1130-4.

[44] Voorhoeve PM, le Sage C, Schrier M, et al. A genetic screen implicates miRNA-372 and miRNA-373 as oncogenes in testicular germ cell tumors. Cell 2006; 124: 1169-81.

[45] Huang Q, Gumireddy K, Schrier M, et al. The microRNAs miR-373 and miR-520c promote tumour invasion and metastasis. Nat Cell Biol 2008; 10: 202-10.

[46] Mitomo S, Maesawa C, Ogasawara S, et al. Downregulation of miR138 is associated with overexpression of human telomerase reverse transcriptase protein in human anaplastic thyroid carcinoma cell lines. Cancer Sci 2008.

[47] Lee DY, Deng Z, Wang CH, Yang BB. MicroRNA-378 promotes cell survival, tumor growth, and angiogenesis by targeting $\mathrm{SuFu}$ and Fus-1 expression. Proc Natl Acad Sci U S A 2007; 104: 20350-5.

[48] Kondoh H, Lleonart ME, Nakashima Y, et al. A high glycolytic flux supports the proliferative potential of murine embryonic stem cells. Antioxid Redox Signal 2007; 9: 293-9.

[49] Gambhir SS. Molecular imaging of cancer with positron emission tomography. Nat Rev Cancer 2002; 2: 683-93.

[50] Evans MJ, Saghatelian A, Sorensen EJ, Cravatt BF. Target discovery in small-molecule cell-based screens by in situ proteome reactivity profiling. Nat Biotechnol 2005; 23: 1303-7. 